\title{
Association of extended myositis panel results, clinical features, and diagnoses: a single-center retrospective observational study
}

\author{
Shamma Ahmad Al Nokhatha ${ }^{1} \cdot$ Eman Alfares $^{2} \cdot$ Luke Corcoran $^{1} \cdot$ Niall Conlon ${ }^{2} \cdot$ Richard Conway $^{1}$ (D)
}

Received: 6 July 2021 / Accepted: 21 September 2021 / Published online: 4 October 2021

(c) The Author(s) 2021

\begin{abstract}
Myositis-specific antibodies (MSA) and myositis-associated antibodies (MAA) are a feature of the idiopathic inflammatory myopathies (IIM), but are also seen in other rheumatic diseases, and in individuals with no clinical symptoms. The aim of this study was to assess the clinical utility of MSA and MAA and in particular the clinical relevance of weakly positive results. We included all patients at our institution who had at least one positive result on the Immunoblot EUROLINE myositis panel over a 6-year period (2015-2020). Associations with clinical features and final diagnosis were evaluated. Eighty-seven of 225 (39\%) myositis panel tests met the inclusion criteria. There were 52 strong positives and 35 weak positives for one or more MSA/MAAs. Among the strong positive group, 15\% (8/52) were diagnosed with IIM, 34.6\% (18/52) with interstitial lung disease, $7.7 \%$ (4/52) with anti-synthetase syndrome, $25 \%$ (13/52) with connective tissue disease, and others accounted for $25 \%$ (13/52). In weak-positive cases, only $14 \%$ (5/35) had connective tissue disease and none had IIM. 60\% (21/35) of weak-positive cases were not associated with a specific rheumatic disease. A significant number of positive myositis panel results, particularly weak positives, are not associated with IIM or CTD.
\end{abstract}

Keywords Myositis $\cdot$ Autoimmune $\cdot$ Antibodies $\cdot$ Inflammatory

\section{Introduction}

The idiopathic inflammatory myopathies (IIM) are a heterogeneous group of autoimmune rheumatic diseases characterized by proximal muscle weakness and frequent involvement of other organ systems [1]. The prevalence of IIM can be estimated between 2.4 and 33.8 per 100,000 persons [2].

Richard Conway

drrichardconway@gmail.com

Shamma Ahmad Al Nokhatha

shamma.alnokhatha@gmail.com

Eman Alfares

Eman.alfaris@yahoo.com

Luke Corcoran

lukepcorcoran@gmail.com

Niall Conlon

NiaConlon@stjames.ie

1 Department of Rheumatology, St. James's Hospital, James's Street, Dublin, Ireland

2 Department of Immunology, St. James's Hospital, James's Street, Dublin, Ireland
Historically, the Bohan and Peter criteria were used for IIM, until 2017 when the European League Against Rheumatism and American College of Rheumatology (EULAR/ ACR) proposed new classification criteria [3, 4]. These new classification criteria reflect the advances of medicine in the last 40 years as well as providing higher performance (sensitivity/specificity, $93 \% / 88 \%$ with biopsies, $87 \% / 82 \%$ without biopsies). The new criteria are based primarily on clinical history, examination, and biopsy results. Only one antibody, Anti-Jo-1, is included. The criteria are in the form of a calculator which gives a probability score of the patient having myositis. A classification tree is then used to help determine the subcategory (polymyositis (PM), dermatomyositis (DM), inclusion body myositis, and juvenile dermatomyositis) [4].

However, autoantibodies have been reported in more than $80 \%$ of patients with IIM. These autoantibodies can be myositis-specific antibodies (MSA), or myositis-associated antibodies (MAA) which are also seen in a host of other connective tissue diseases (CTD). MSA have a 90\% diagnostic specificity, while MAA are noted in up to $50 \%$ of myositis patients. These antibodies can help anticipate the clinical course and disease prognosis $[5,6]$. 
MSA include anti-ARS (aminoacyl-tRNA synthetases) antibodies; (histidyl (Jo-1), threonyl (PL-7), alanyl (PL-12), glycyl (EJ), isoleucyl (OJ), asparaginyl (KS), tyrosyl (Ha), and phenylalanyl (Zo)), anti-Mi2 (nucleosome-remodeling deacetylase complex), anti-SRP (signal recognition particle), anti-TIF1 (transcription intermediary factor 1) and antiNXP-2 (nuclear matrix protein 2), anti-MDA5 (melanoma differentiation-associated protein 5), and anti-SAE (small ubiquitin-like modifier activating enzyme). MAA include anti-PM-Scl, U1RNP, Ku, and Ro52 [7-9].

Autoantibodies are a feature of the subclinical phase of systemic rheumatic diseases and can be present for many years before the onset of clinical symptoms $[10,11]$. MSA and MAA are associated with IIM; however, only anti Jo- 1 is included in the EULAR/ACR criteria. Weak-positive MSA/ MAA are frequently seen and of uncertain clinical significance. Therefore, the aim of the study is to assess the clinical utility of MSA and MAA and in particular the clinical relevance of weakly positive results.

\section{Materials and methods}

\section{Study design and setting}

This study is a single-center retrospective observational study, performed over a 6-year period (2015-2020). All patients who had an extended myositis antibody panel in this period were assessed for eligibility. Those over age 18 with at least one positive MSA/MAA were included and patients who were followed up in other institutions were excluded. IIM patients with positive MSA/MAA were compared to weak-positive MSA/MAA patients. The study was approved by the St. James' Hospital (SJH)/Tallaght University Hospital (TUH) Joint Research Ethics Committee under protocol number 2020-04 List 15, in May 2020.

\section{Determination/procedure}

Myositis antibody testing was performed using the Immunoblot EUROLINE myositis panel, according to the manufacturer's specifications. This assay allows the detection of human IgG autoantibodies to a range of different antigens. This includes 12 MSA (Mi-2a, Mi-2b, TIF1, MDA5, NXP2, SAE1, SRP, Jo-1, PL-7, PL-12, EJ, and OJ), in addition to 4 MAA (Ku, PM-Scl100, PM-Scl75, and Ro/SSA-52). Our immunology lab reports PM-Scl100 and PM-Scl75 separately. Some consider both anti-PM-Scl100 and anti-PMScl75 antibodies as one, since they target two closely related isoforms of the same protein. For the purpose of this study, we have included those who were positive for PM-Scl75 and/or PM-Scl100 under the one result. The same applies for Mi-2a and Mi-2b [12]. Anti-nuclear antibody (ANA) screening by indirect immunofluorescence (IIF) on HEp-2 cells is performed in tandem with each myositis panel to improve specificity, as some myositis antibodies have a distinct ANA staining pattern [13]. The assay was performed according to the manufacturer's recommendations, using a screening dilution of 1:80. Comments are on the presence or absence of antibodies, in addition to the pattern.

\section{Measurement}

Immunoblot strips were analyzed using the EuroBlotOne Analyzer/Euroline Scan. This assay provides a semi-qualitative result based on signal intensity of each measured antibody. Results are reported as: negative, weak positive, and strong positive. According to the manufacturer's recommendations, an antibody is considered negative if the signal is $<11$. Low positivity is a signal between 11 and 25 , and strong positivity beyond 25 . The turnover time for the assay is 21 days.

\section{Clinical features}

Clinical features were defined as follows. Interstitial lung disease was diagnosed by a respiratory physician. Other features were identified by a rheumatologist and/or immunologist. Arthritis was defined as swelling and tenderness of one or more joints, arthralgia as joint pain with no evidence of arthritis, myositis as muscle weakness supported by relevant investigations, Raynaud's phenomenon as recurrent events of sharply demarcated pallor and/or cyanosis of the skin of the digits with or without reactive hyperaemia, and cutaneous manifestations as Gottron's papules or sign, heliotrope rash, photosensitive rash, calcinosis, digital ulceration, psoriasis, livedo reticularis, or sclerodactyly. Malignancy was defined as any cancer within 5 years of the index study.

\section{Statistical analysis}

Statistical analysis was performed using SPSS v26. Descriptive statistics were reported, with results given as frequency and percentages. Categorical variables were compared using Chi-square tests. $p \leq 0.05$ was considered statistically significant throughout.

\section{Results}

\section{Patients and demographics}

A total of 225 myositis panels were performed in the 6-year study period. 87/225 (39\%) patients had positive myositis panel results and met the inclusion criteria, $39 \%$ were male and $61 \%$ female, with a mean (SD) age of $58(+-16)$ years. 
Of the positive results, $60 \%$ (52/87) were strong positive for and 40\% (35/87) weak positive for one or more MSA/ MAAs. Full demographic data are shown seen in Table 1 (strong positive cohort) and Table 2 (weak-positive cohort).

\section{Clinical features}

Tables 1 and 2 summarize the clinical features, ANA results, medication, and outcome of included cases. A creatine kinase (CK) level was performed in $52 \%$ of patients, with a median result of 69 (IQR 44.5-277, $p=0.57$ ). Respiratory medicine accounted for the highest number of test requests $(33 \%, 29 / 87)$, followed by rheumatology and immunology (24\%, 21/87 each).

\section{Strong-positive MSA/MAA}

Anti-PL12 was the most frequent strong positive MSA and anti-Ro52 the most common strong positive MAA (Table 3). The most frequently observed clinical features were arthralgia in 38\% (20/52), ILD in 35\% (18/52), and cutaneous manifestations in 29\% (15/52). Arthritis was seen in $15 \%$ (8/52), Raynaud's phenomenon in $15 \%$ (8/52), myositis in $13 \%$ (7/52), and malignancy in $12 \%(6 / 52)$. Thirteen percent $(8 / 52)$ were diagnosed with dermatomyositis and $8 \%(4 / 52)$ with anti-synthetase syndrome.

\section{Weak-positive MSA/MAA}

Anti-Mi2 was the most frequent weak-positive MSA and anti-Ro52 the most frequent weak-positive MAA (Table 3). The most common clinical manifestations were ILD in $34 \%$ (12/35), cutaneous manifestations in 20\% (7/35), and arthralgia in $17 \%$ (6/35), with Raynaud's phenomenon and arthritis in $11 \%$ each (4/35) and myositis and malignancy in 3\% (1/35) each. No patients were diagnosed with IIM or anti-synthetase syndrome.

\section{Clinical correlates of positive MSA/MAA}

A statistically significant association between arthralgia and a positive myositis panel was identified $(p=0.033)$ (Table 4). There were numerical differences for presentations of ILD ( $p=0.975)$, myositis ( $p=0.093)$, and cutaneous $(p=0.140)$ manifestations, but these did not reach statistical significance. A diagnosis of IIM was associated with a strong positive panel $(p=0.008)$. Symptom duration $<1$ year was associated with a weakly positive panel $(p=0.022)$.

Details of clinical features and diagnosis by individual MSA and MAA are shown in Supplementary Tables 1-7. There was no evident difference between single MSA/MAA positivity and positivity for more than one MSA/MAA and clinical features or diagnosis.

\section{Discussion}

Our study shows that those with a strong positive myositis panel were more likely to be diagnosed with an IIM and were more likely to present with arthralgia. There were no diagnoses of IIM in the weakly positive myositis panel group.

A review of the literature shows variations of clinical presentation and serology across different populations. It is felt that genetic factors and environmental triggers may be responsible for this disparity [14]. For example, a study of a Greek population found that the most frequently detected MAA was anti-Ro-52 (30\%), while the most frequently detected MSA was anti-Jo-1 (22\%) [15]. In our total population, only $3 \%$ tested positive for anti-Jo-1.

Our study shows the association of MSA and MAA with IIM, ILD, and CTD are much higher at the strong positive antibody level when compared with the weak positive. However, the diagnostic yield of MSA was generally lower than previously reported studies $[16,17]$. This may be because of a relatively short follow-up in our population compared to other published studies or may be due to testing in patients with a lower pre-test probability.

The American thoracic society/European respiratory society/Japanese respiratory society/Latin American thoracic society diagnostic guidelines recommend serial antibody testing in ILD to identify seroconversion and differentiate idiopathic pulmonary fibrosis (IPF) from CTD-ILD. In our study, $34 \%$ of all patients were diagnosed with ILD and respiratory having the highest number of requests. This shows the value of MSA testing in ILD as it may present with no or minimal symptoms suggestive of CTD [18]. As CTD- ILD confers a better prognosis and different treatment approach than IPF, it is of paramount importance to detect this subset at an early stage [19].

In our study, MSA were detected in many other inflammatory and non-inflammatory diseases. This finding is in contrast to the majority of prior studies. For instance, Vulseteke et al. reported positive MSA in half of patients with IIM compared to only $3.5 \%$ of patients with systemic inflammatory diseases and none in healthy controls [20]. This could suggest that MSA sensitivity and specificity vary from one testing lab to another $[15,16]$. It may also be the case that there are differences in the populations being tested, with resultant variation in the pre-test probability.

We perform ANA in conjunction with the myositis panel to improve diagnostic performance [13]. 83\% of weakly positive myositis panels in our cohort were ANA negative compared to $46 \%$ of strong positive panels ( $93 \%$ correctly matched the non-ANA staining in the positive panel). A false-positive test should be considered if the autoantibody staining/pattern does not correlate with the ANA result and 


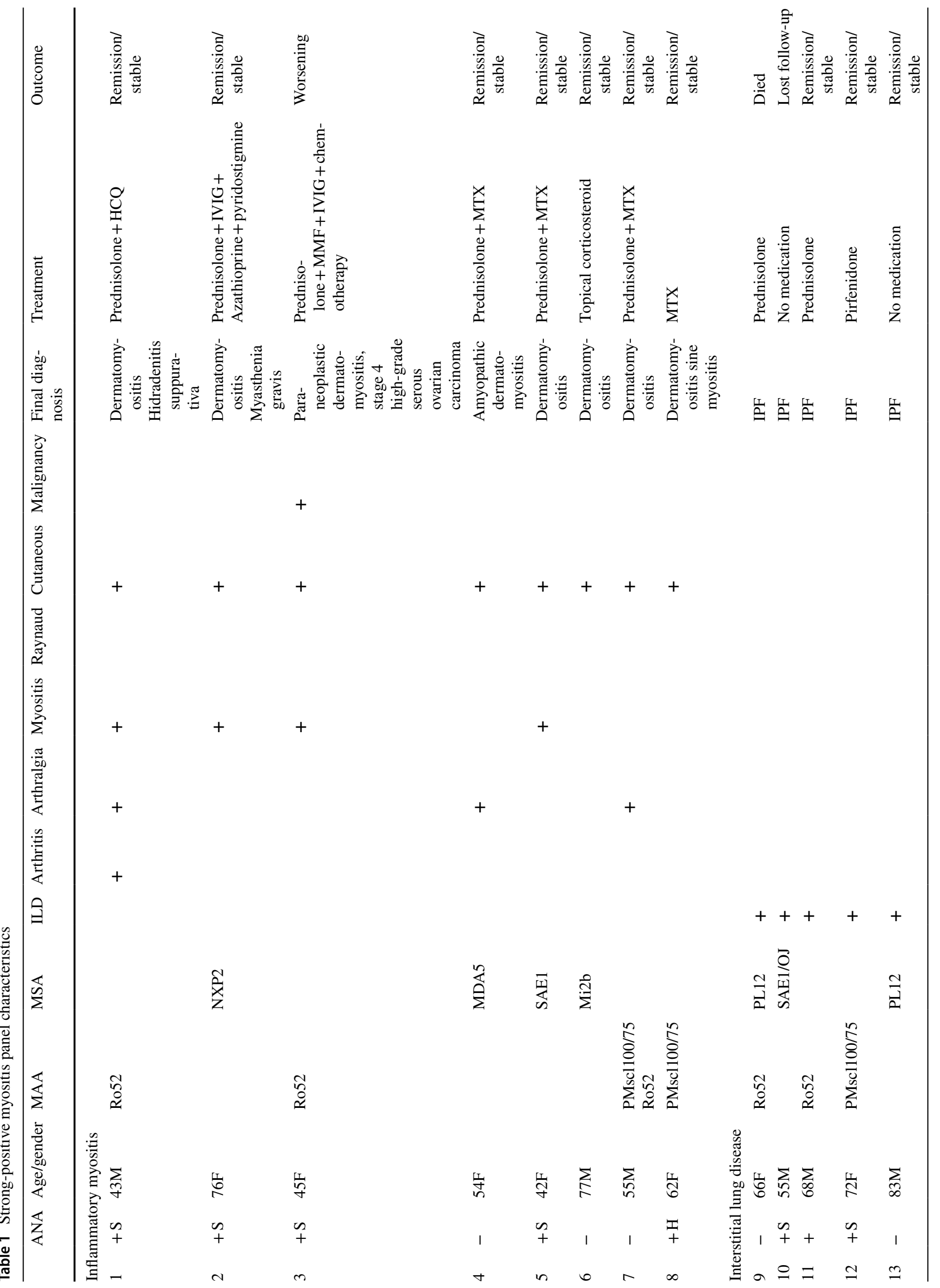




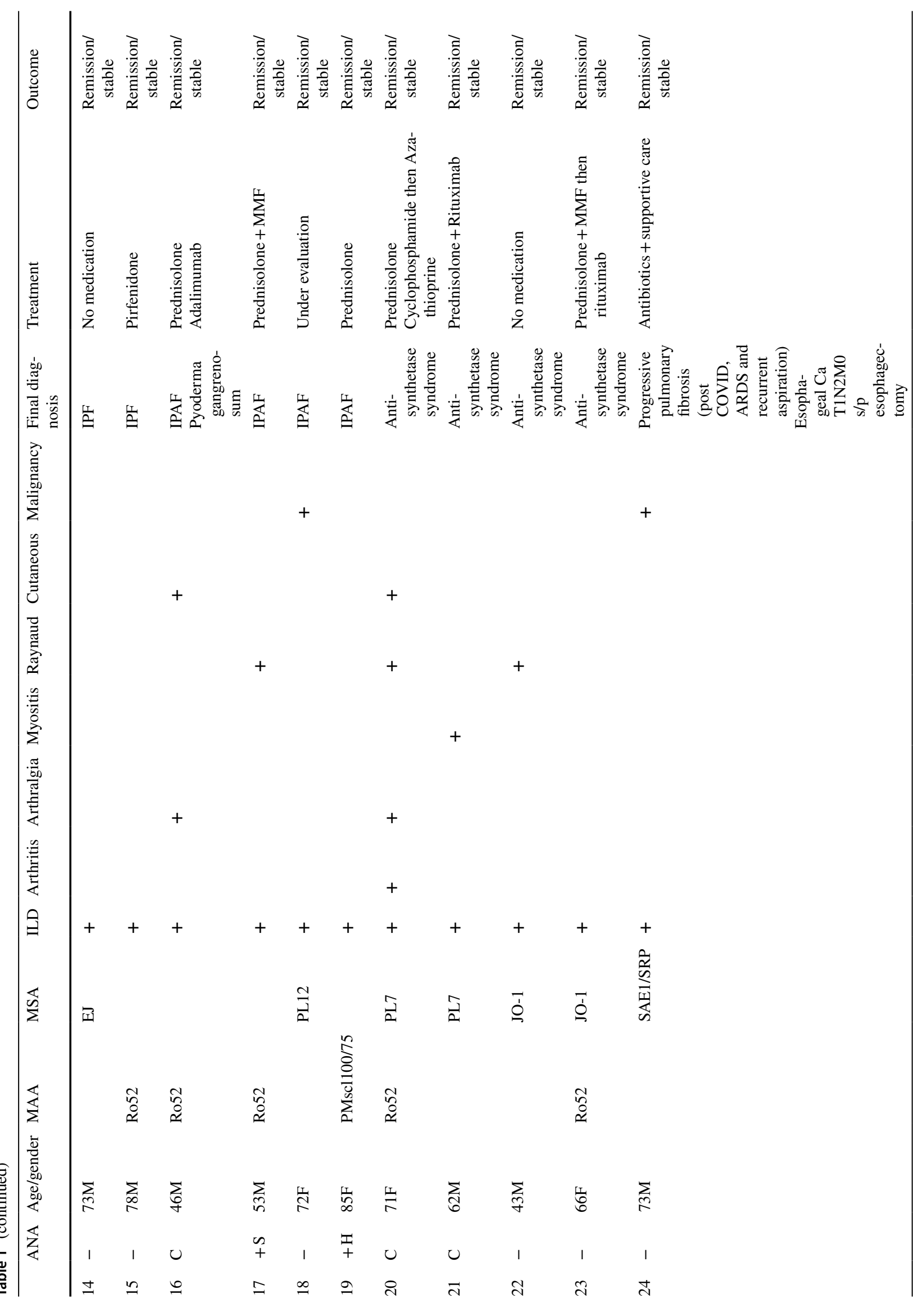




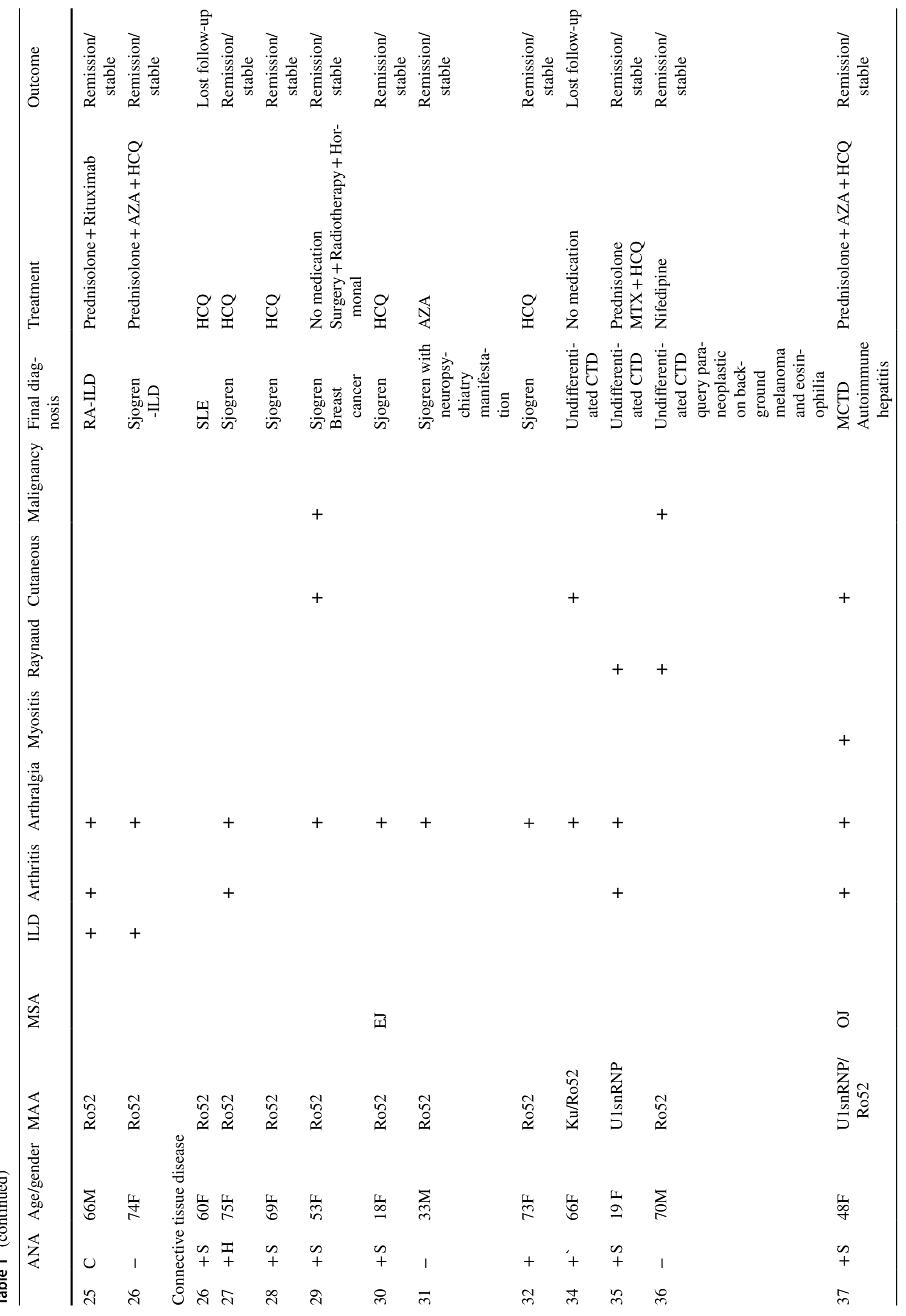




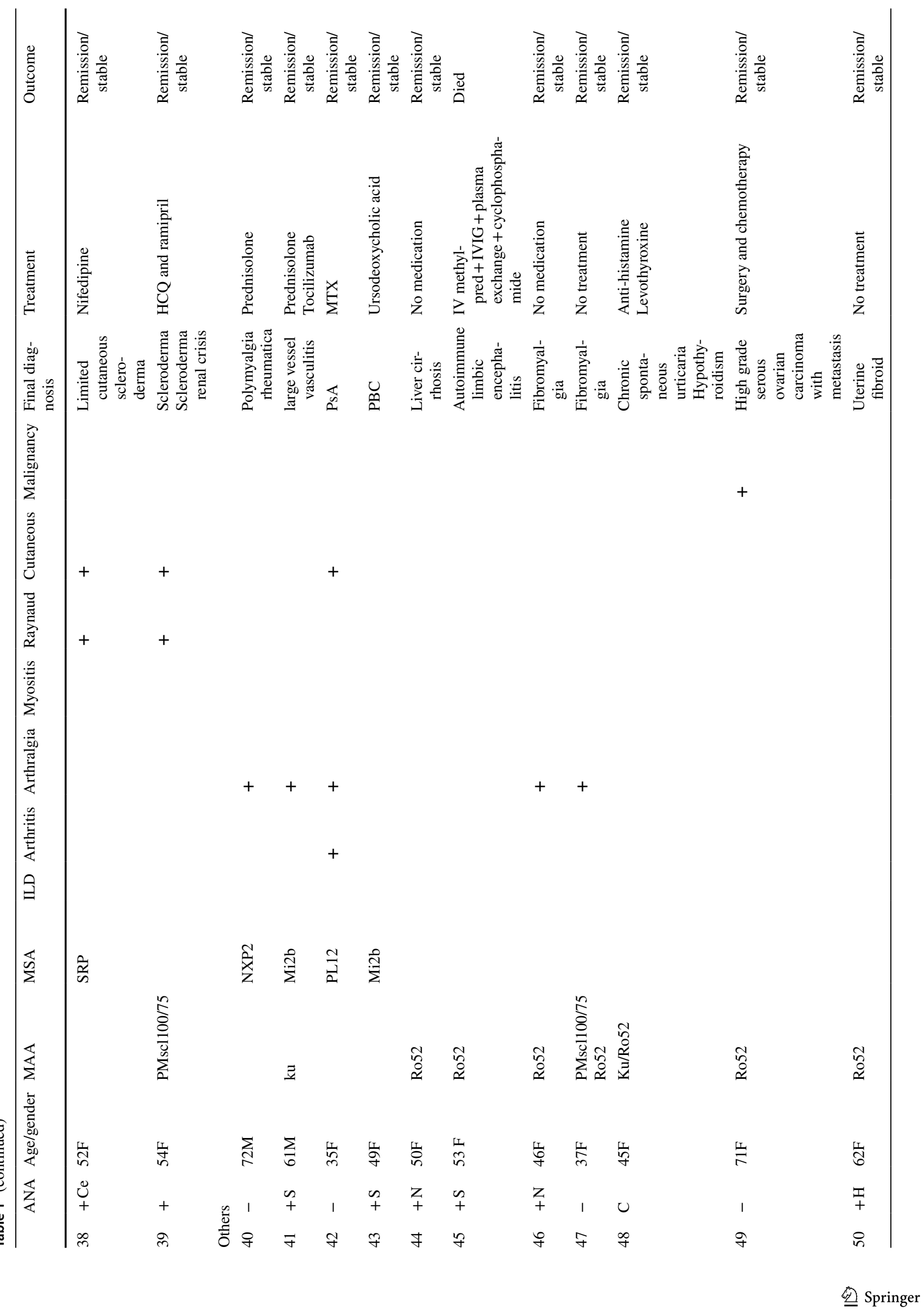




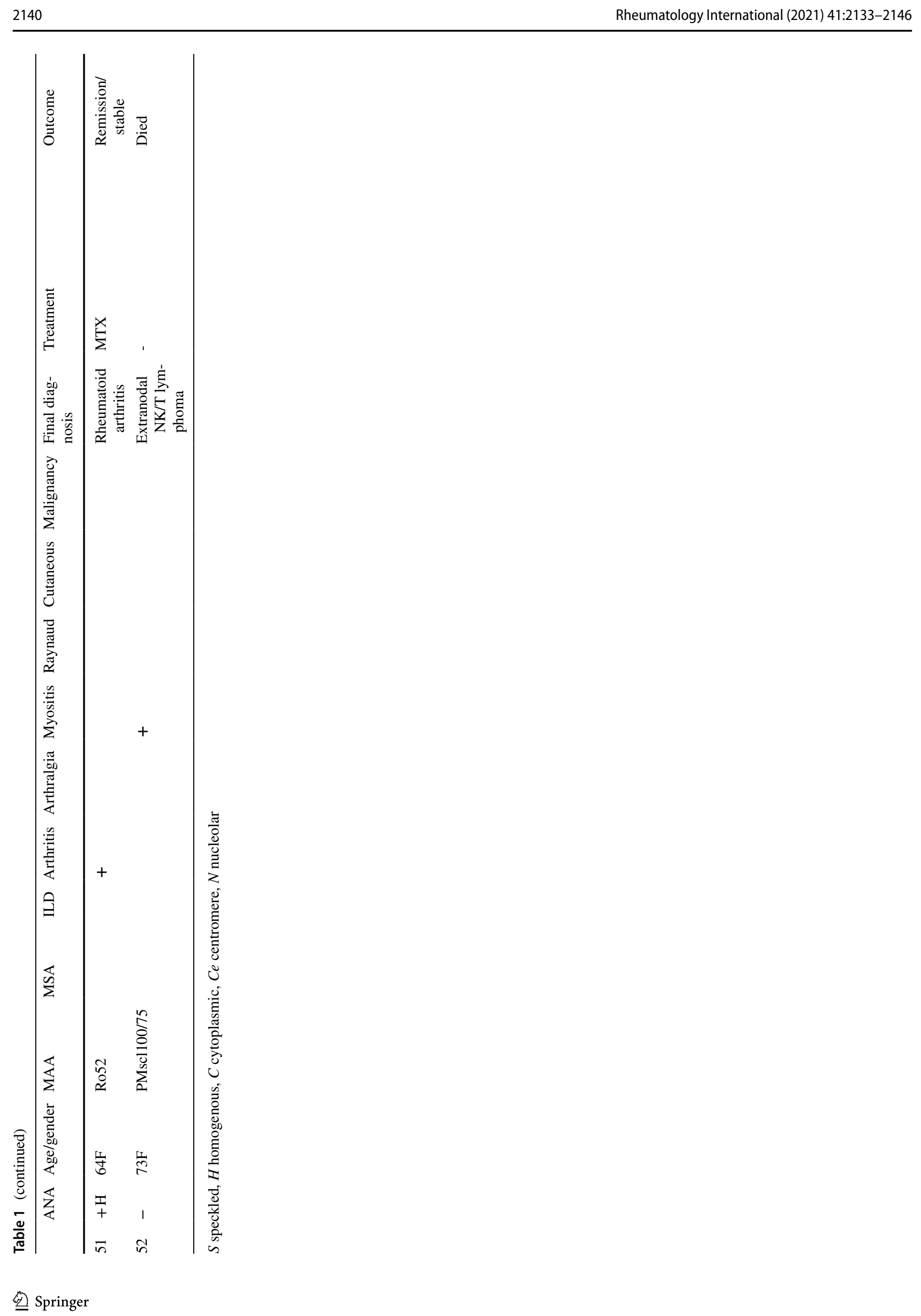




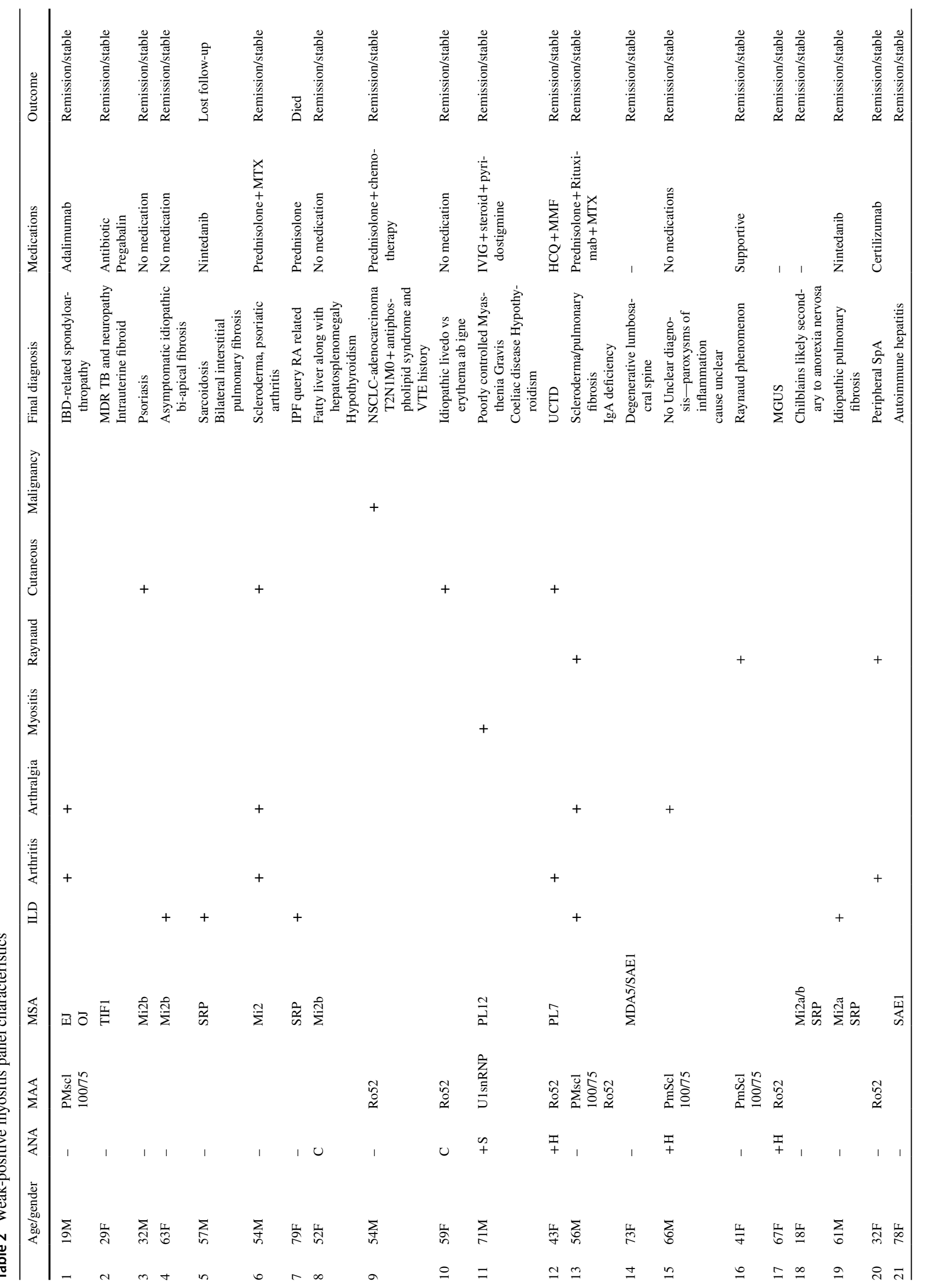




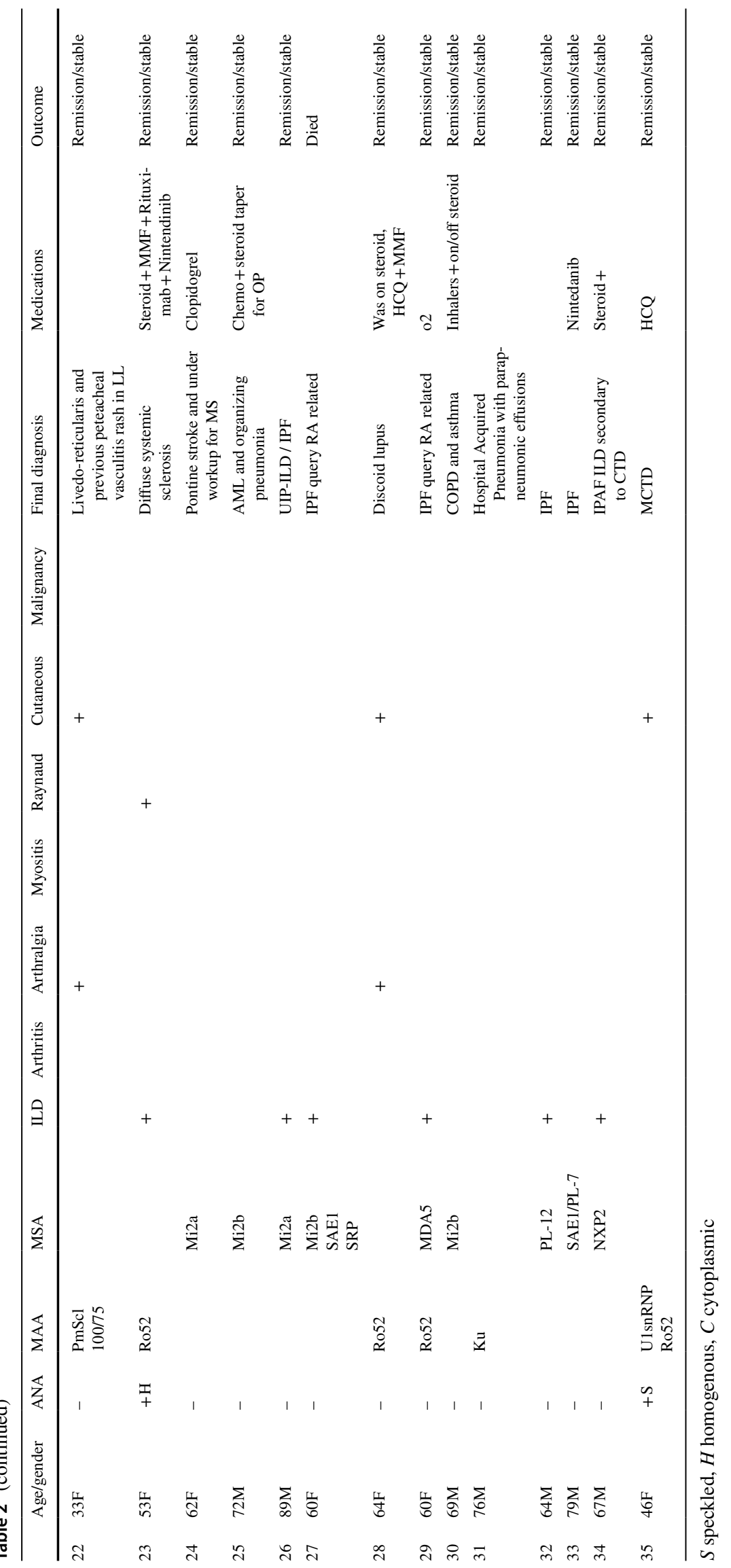


Table3 The results of the antibodies for both positive and weakly positive

\begin{tabular}{lll}
\hline Antibody & Positive & $\begin{array}{l}\text { Weakly } \\
\text { positive }\end{array}$ \\
\hline MSA & & \\
Anti-PL-12 & 4 & 2 \\
Anti-SAE1 & 3 & 3 \\
Anti-Mi2 & 3 & 12 \\
Anti-NXP2 & 2 & 1 \\
Anti-Jo & 2 & 1 \\
Anti-SRP & 2 & 5 \\
Anti-PL7 & 2 & 2 \\
Anti-EJ & 2 & 1 \\
Anti-OJ & 2 & 1 \\
Anti-MDA5 & 1 & 2 \\
MAA & & \\
Anti-Ro52 & 29 & 10 \\
Anti-PMScl & 7 & 5 \\
Anti-Ku & 3 & - \\
Anti-U1RNP & 2 & 2 \\
\hline
\end{tabular}

clinical context [9]. However, some MSA exhibit negative ANA testing due to cytoplasmic localisation, and as such negative ANA does not necessarily imply autoantibody negativity in IIM.

This study was not without its limitations. Our power to detect significant differences was impacted by a relatively small sample size and low number of IIM diagnoses. This highlights the need for larger collaborative studies to evaluate these rare conditions. This was a single-center study and our findings require confirmation in other settings to confirm external validity. Given the significant mortality and morbidity burden of IIM, early and accurate diagnosis should be a primary goal in all cases. Based on the above, we have proposed an algorithm to guide the interpretation of myositis antibody panel results, Fig. 1. This highlights our findings and suggests that weak-positive panels should be repeated to confirm the result.

The current EULAR/ACR guidelines suggest that clinical assessment and biopsy are the core components of the diagnostic approach to IIM. Our expanding knowledge of the importance of MSA/MAA suggests a key adjunctive role in diagnosis. Our study found that positive panels are more likely to be associated with IIM; however, a significant number of cases had no clinical features suggestive of CTD or IIM. A combined clinical and serological framework may be useful in IIM diagnosis. 
Table 4 Chi-square analysis between weak-positive and positive myositis panel

\begin{tabular}{|c|c|c|c|c|c|}
\hline & \multicolumn{4}{|l|}{ Type } & \multirow[t]{3}{*}{$p$ value } \\
\hline & \multicolumn{2}{|c|}{$\begin{array}{l}\text { Weak-positive myositis } \\
\text { panel }\end{array}$} & \multicolumn{2}{|c|}{ Positive myositis panel } & \\
\hline & Count & Column $N \%$ & Count & Column $N \%$ & \\
\hline ILD & 12 & 34.3 & 18 & 34.6 & 0.975 \\
\hline Arthritis & 4 & 11.4 & 8 & 15.4 & 0.600 \\
\hline Arthralgia & 6 & 17.1 & 20 & 38.5 & $0.033^{*}$ \\
\hline Myositis & 1 & 2.9 & 7 & 13.5 & 0.093 \\
\hline Raynaud & 4 & 11.4 & 8 & 15.4 & 0.600 \\
\hline Cutaneous & 7 & 20.0 & 18 & 34.6 & 0.140 \\
\hline Malignancy & 1 & 2.9 & 6 & 11.5 & 0.144 \\
\hline \multicolumn{6}{|l|}{ Final diagnosis } \\
\hline Inflammatory myositis & 0 & 0.0 & 8 & 15.4 & \multirow[t]{4}{*}{$0.008^{*}$} \\
\hline Interstitial lung disease & 12 & 34.3 & 18 & 34.6 & \\
\hline Connective tissue disease & 5 & 14.3 & 14 & 26.9 & \\
\hline Others & 18 & 51.4 & 12 & 23.1 & \\
\hline \multicolumn{6}{|l|}{ Management } \\
\hline Corticosteroid & 3 & 8.6 & 5 & 9.6 & \multirow[t]{5}{*}{0.115} \\
\hline Corticosteroid + immunosuppression & 7 & 20.0 & 17 & 32.7 & \\
\hline Immunosuppression & 3 & 8.6 & 12 & 23.1 & \\
\hline No treatment & 11 & 31.4 & 9 & 17.3 & \\
\hline Others & 11 & 31.4 & 9 & 17.3 & \\
\hline \multicolumn{6}{|l|}{ Outcome } \\
\hline Died & 2 & 5.7 & 3 & 5.8 & \multirow[t]{4}{*}{0.773} \\
\hline Remission/stable & 32 & 91.4 & 45 & 86.5 & \\
\hline Worsening & 0 & 0.0 & 1 & 1.9 & \\
\hline Lost follow-up & 1 & 2.9 & 3 & 5.8 & \\
\hline \multicolumn{6}{|l|}{ Duration } \\
\hline$=<1$ year & 23 & 65.7 & 22 & 42.3 & \multirow[t]{5}{*}{$0.022 *$} \\
\hline 2 years & 6 & 17.1 & 14 & 26.9 & \\
\hline 3 years & 6 & 17.1 & 5 & 9.6 & \\
\hline 4 years & 0 & 0.0 & 8 & 15.4 & \\
\hline 5 years & 0 & 0.0 & 3 & 5.8 & \\
\hline
\end{tabular}

$* p<0.05$ 


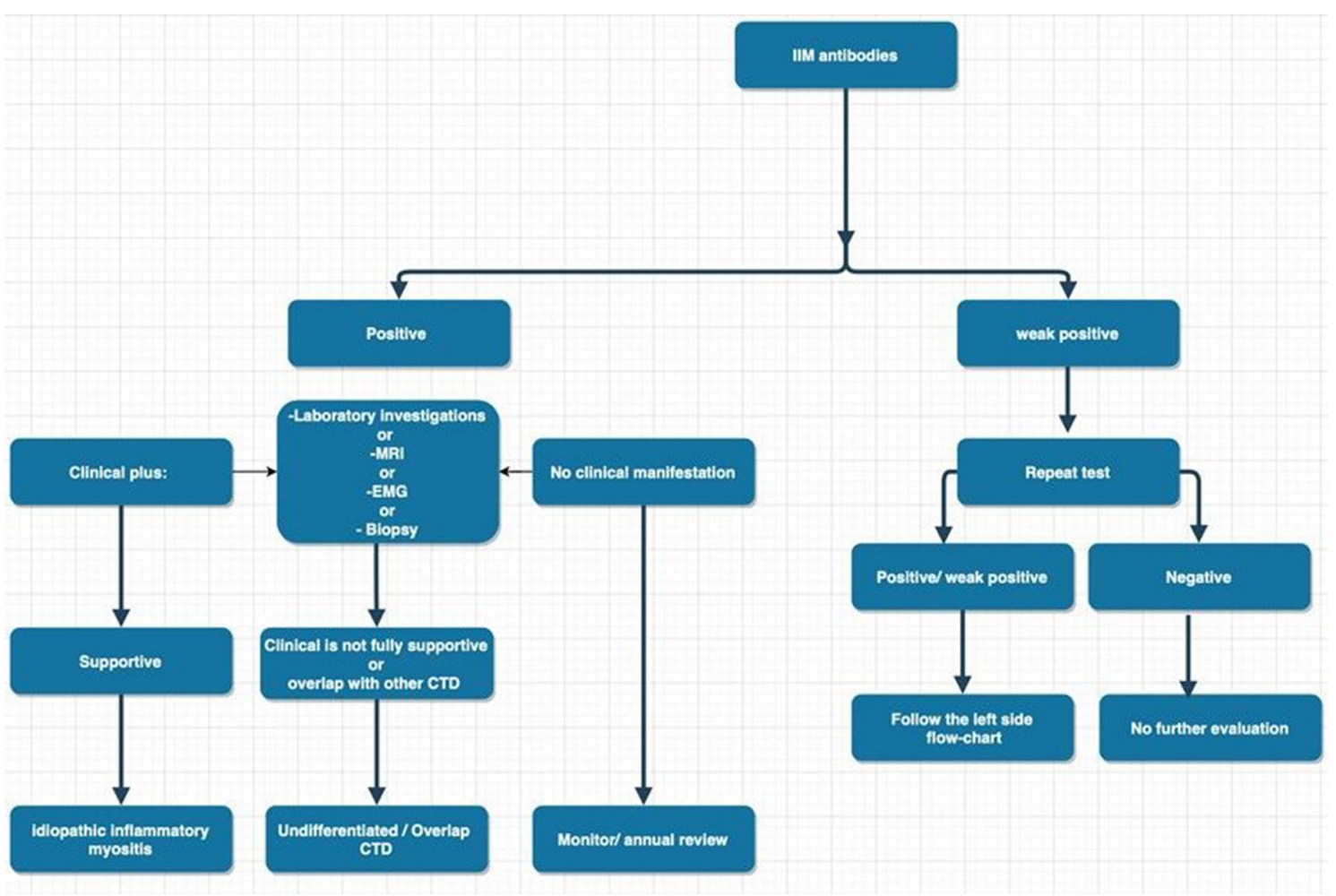

Fig. 1 A proposed algorithm to guide interpretation of myositis antibody panel results

Supplementary Information The online version contains supplementary material available at https://doi.org/10.1007/s00296-021-05012-0.

Author contributions SAN, NC, and RC: substantial contributions to the conception or design of the work and the acquisition, analysis, and interpretation of data for the work; and drafting the work or revising it critically for important intellectual content; and final approval of the version to be published; and agreement to be accountable for all aspects of the work in ensuring that questions related to the accuracy or integrity of any part of the work are appropriately investigated and resolved. EA and LC: substantial contributions to the acquisition, analysis, and interpretation of data for the work; and drafting the work or revising it critically for important intellectual content; and final approval of the version to be published; and agreement to be accountable for all aspects of the work in ensuring that questions related to the accuracy or integrity of any part of the work are appropriately investigated and resolved.

Funding Open Access funding provided by the IReL Consortium. None.

Availability of data and materials Available from authors on request.

Code availability Not applicable.

\section{Declarations}

Conflict of interest The authors declare that they have no conflict of interst.
Open Access This article is licensed under a Creative Commons Attribution 4.0 International License, which permits use, sharing, adaptation, distribution and reproduction in any medium or format, as long as you give appropriate credit to the original author(s) and the source, provide a link to the Creative Commons licence, and indicate if changes were made. The images or other third party material in this article are included in the article's Creative Commons licence, unless indicated otherwise in a credit line to the material. If material is not included in the article's Creative Commons licence and your intended use is not permitted by statutory regulation or exceeds the permitted use, you will need to obtain permission directly from the copyright holder. To view a copy of this licence, visit http://creativecommons.org/licenses/by/4.0/.

\section{References}

1. Firestein G, Budd R, Gabriel S, McInnes I, O’Dell J (2017) Kelley's textbook of rheumatology. Elsevier, Philadelphia

2. Meyer A, Meyer N, Schaeffer M, Gottenberg JE, Geny B, Sibilia J (2015) Incidence and prevalence of inflammatory myopathies: a systematic review. Rheumatology (Oxford) 54:50-63. https://doi. org/10.1093/rheumatology/keu289

3. Bohan A, Peter JB (1975) Polymyositis and dermatomyositis (first of two parts). N Engl J Med 292:344-347. https://doi.org/10.1056/ nejm197502132920706

4. Lundberg IE, Tjärnlund $\mathrm{A}$, Bottai $\mathrm{M}$, Werth VP, Pilkington $\mathrm{C}$, Visser M, Alfredsson L, Amato AA, Barohn RJ, Liang MH, Singh JA, Aggarwal R, Arnardottir S, Chinoy H, Cooper RG, Dankó K, Dimachkie MM, Feldman BM, Torre IG, Gordon P, Hayashi T, 
Katz JD, Kohsaka H, Lachenbruch PA, Lang BA, Li Y, Oddis CV, Olesinska M, Reed AM, Rutkowska-Sak L, Sanner H, SelvaO'Callaghan A, Song YW, Vencovsky J, Ytterberg SR, Miller FW, Rider LG (2017) 2017 European League Against Rheumatism/ American College of Rheumatology classification criteria for adult and juvenile idiopathic inflammatory myopathies and their major subgroups. Ann Rheum Dis 76:1955-1964. https://doi.org/ 10.1136/annrheumdis-2017-211468

5. Cruellas MG, Viana Vdos S, Levy-Neto M, Souza FH, Shinjo SK (2013) Myositis-specific and myositis-associated autoantibody profiles and their clinical associations in a large series of patients with polymyositis and dermatomyositis. Clinics (Sao Paulo) 68:909-914. https://doi.org/10.6061/clinics/2013(07)04

6. Ghirardello A, Borella E, Beggio M, Franceschini F, Fredi M, Doria A (2014) Myositis autoantibodies and clinical phenotypes. Auto Immun Highlights 5:69-75. https://doi.org/10.1007/ s13317-014-0060-4

7. Chino H, Sekine A, Baba T, Iwasawa T, Okudela K, Takemura T, Itoh H, Sato S, Suzuki Y, Ogura T (2016) Radiological and pathological correlation in anti-MDA5 antibody-positive interstitial lung disease: rapidly progressive perilobular opacities and diffuse alveolar damage. Intern Med (Tokyo, Japan). 55:2241-2246. https://doi.org/10.2169/internalmedicine.55.5774

8. Mahler M, Miller FW, Fritzler MJ (2014) Idiopathic inflammatory myopathies and the anti-synthetase syndrome: a comprehensive review. Autoimmun Rev 13:367-371. https://doi.org/10.1016/j. autrev.2014.01.022

9. Palterer B, Vitiello G, Carraresi A, Giudizi MG, Cammelli D, Parronchi P (2018) Bench to bedside review of myositis autoantibodies. Clin Mol Allergy 16:5. https://doi.org/10.1186/ s12948-018-0084-9

10. Ma WT, Chang C, Gershwin ME, Lian ZX (2017) Development of autoantibodies precedes clinical manifestations of autoimmune diseases: a comprehensive review. J Autoimmun 83:95-112. https://doi.org/10.1016/j.jaut.2017.07.003

11. Vulsteke JB, Blockmans D, Moons V, Vijgen S, Bossuyt X, De Langhe E (2020) Detection of anti-Mi-2 autoantibodies before dermatomyositis-specific manifestations. Rheumatology (Oxford) 59:e60-e62. https://doi.org/10.1093/rheumatology/keaa055

12. Lecouffe-Desprets M, Hémont C, Néel A, Toquet C, Masseau A, Hamidou M, Josien R, Martin JC (2018) Clinical contribution of myositis-related antibodies detected by immunoblot to idiopathic inflammatory myositis: a one-year retrospective study. Autoimmunity 51:89-95. https://doi.org/10.1080/08916934.2018.14418 30

13. Damoiseaux J, Andrade LEC, Carballo OG, Conrad K, Francescantonio PLC, Fritzler MJ, Garcia de la Torre I, Herold M, Klotz W, Cruvinel WM, Mimori T, von Muhlen C, Satoh M, Chan EK (2019) Clinical relevance of HEp-2 indirect immunofluorescent patterns: the International Consensus on ANA patterns (ICAP) perspective. Ann Rheum Dis 78:879-889. https://doi.org/10.1136/ annrheumdis-2018-214436

14. Alenzi FM (2020) Myositis specific autoantibodies: a clinical perspective. Open Access Rheumatol 12:9-14. https://doi.org/ 10.2147/oarrr.S231195

15. Zampeli E, Venetsanopoulou A, Argyropoulou OD, Mavragani CP, Tektonidou MG, Vlachoyiannopoulos PG, Tzioufas AG, Skopouli FN, Moutsopoulos HM (2019) Myositis autoantibody profiles and their clinical associations in Greek patients with inflammatory myopathies. Clin Rheumatol 38:125-132. https://doi.org/ 10.1007/s10067-018-4267-z

16. Platteel ACM, Wevers BA, Lim J, Bakker JA, Bontkes HJ, Curvers J, Damoiseaux J, Heron M, de Kort G, Limper M, van Lochem EG, Mulder AHL, Saris CGJ, van der Valk H, van der Kooi AJ, van Leeuwen EMM, Veltkamp M, Schreurs MWJ, Meek B, Hamann D (2019) Frequencies and clinical associations of myositis-related antibodies in The Netherlands: a one-year survey of all Dutch patients. J Transl Autoimmun 2:100013. https://doi.org/10. 1016/j.jtauto.2019.100013

17. González-Bello Y, Garcia-Valladares I, Reyes-Pérez IV, GarcíaCerda D, Medrano-Ramírez G, Navarro-Zarza JE, AndradeOrtega L, Maradiaga-Ceceña M, Cardenas-Anaya A, Nava-Zavala AH, Orozco-Barocio G, Vázquez-Del Mercado M, Rojo-Mejia A, Loyo E, Gottschalk P, Iglesias-Gamarra A, Vega K, Rojas C, Mantilla R, Gómez G, García-Kutzbach A, Fritzler MJ, García-De La Torre I (2020) Myositis-specific antibodies and myositis-associated antibodies in patients with idiopathic inflammatory myopathies from the PANLAR myositis study group. J Clin Rheumat. https://doi.org/10.1097/rhu.0000000000001350

18. De Sadeleer LJ, De Langhe E, Bodart N, Vigneron A, Bossuyt X, Wuyts WA (2018) Prevalence of myositis-specific antibodies in idiopathic interstitial pneumonias. Lung 196:329-333. https:// doi.org/10.1007/s00408-018-0108-8

19. Yoshimura K, Kono M, Enomoto Y, Nishimoto K, Oyama Y, Yasui H, Hozumi H, Karayama M, Suzuki Y, Furuhashi K, Enomoto N, Fujisawa T, Nakamura Y, Inui N, Sumikawa H, Johkoh T, Colby TV, Sugimura H, Suda T (2018) Distinctive characteristics and prognostic significance of interstitial pneumonia with autoimmune features in patients with chronic fibrosing interstitial pneumonia. Respir Med 137:167-175. https://doi.org/10.1016/j. rmed.2018.02.024

20. Vulsteke J-B, Bossuyt X, Dillaerts D, Poesen K, Claeys K, Lenaerts J, Westhovens R, Blockmans D, Haes PD, Langhe ED (2017) FRI0393 Prevalence of myositis-specific antibodies in idiopathic inflammatory myopathy compared to disease and healthy controls. Ann Rheumat Dis 76:636-637. https://doi.org/10.1136/annrheumdis-2017-eular.5143

Publisher's Note Springer Nature remains neutral with regard to jurisdictional claims in published maps and institutional affiliations. 